\title{
Aplikasi Pemesanan Tempat Restoran Kota Palembang
}

\author{
Irma Salamah', Nasron ${ }^{2}$, Nurul Hidayah Shafariah ${ }^{3}$ \\ Teknik Elektro Politeknik Negeri Sriwijaya \\ Jl. Srijaya Negara Bukit Besar, Palembang \\ 1irma.slamah@yahoo.com, 2nasron6819@gmail.com, ${ }^{3}$ nurulhidayahshafariah@gmail.com
}

\begin{abstract}
Palembang is the capital of the province of South Sumatra that has a diverse culture, beautiful tourist attractions and has a distinctive culinary flavor. Usually, culinary tourism becomes the main attraction for tourists when visiting an area. Culinary attractions that are often visited by tourists such as restaurants, restaurants, cafes, etc. This application aims to help staff handle orders from the surge of tourists who arrive, as well as help and make it easier for tourists to find restaurant information, restaurant places, place bookings, and choose the desired menu. This application is an ordering application for a restaurant in the city of Palembang that uses Android as a data communication process and uses notifications as its statement. This application was built using the waterfall method as an application development method so that it can facilitate the design process. This application is expected to facilitate tourists and employees in the process of booking a place in the city of Palembang.
\end{abstract}

Keywords: Booking a place, restaurant, Android, Waterfall, UML

\begin{abstract}
Abstrak
Palembang merupakan ibu kota provinsi Sumatera Selatan yang memiliki kebudayaan yang beraneka ragam, tempat-tempat wisata yang indah dan memiliki cita rasa kuliner yang khas. Biasanya, wisata kuliner menjadi ketertarikan utama bagi para wisatawan ketika berkunjung ke suatu daerah. Tempat wisata kuliner yang sering dikunjungi para wisatawan seperti rumah makan, restoran, café, dll. Aplikasi ini bertujuan untuk membantu para staf karyawan dalam menangani pesanan dari lonjakan para wisatawan yang berdatangan, serta membantu dan mempermudah para wisatawan dalam mencari informasi restoran, tempat restoran, melakukan pembookingan tempat, dan memilih menu yang diinginkan. Aplikasi ini merupakan aplikasi pemesanan tempat restoran kota Palembang yang menggunakan android sebagai proses komunikasi data dan menggunakan notifikasi sebagai konfirmansinya. Aplikasi ini dibangun menggunakan metode waterfall sebagai metode pengembangan aplikasi sehingga dapat memudahkan dalam proses perancangan. Aplikasi ini diharapkan dapat memudahkan wisatawan dan karyawan dalam proses pemesanan tempat di kota Palembang.
\end{abstract}

Kata Kunci: Pemesanan tempat, Restoran, Android, Waterfall, UML

\section{PENDAHULUAN}

Di era modern ini, perkembangan teknologi dan komunikasi yang sangat pesat dapat memberikan dampak besar pada setiap aspek kehidupan dimulai dari aspek agama hingga masuk ke aspek bisnis. Dalam aspek bisnis, teknologi media 
mobile dapat memberikan keuntungan dan kemudahan dalam berbisnis sehingga dapat menghemat waktu dan tenaga. Salah satu media mobile yang berdasarkan pada sistem operasinya adalah android. Berdasarkan laporan yang bertajuk Global Stashot, di seluruh penjuru dunia sistem operasi android saat ini telah mendominasi perangkat bergerak [1].

Hal ini dikarenakan Android merupakan sistem operasi untuk telepon seluler berbasis linux yang menyediakan platform terbuka (open source) bagi para pengembang untuk menciptakan aplikasi mereka sendiri [2]. Dengan pertumbuhan android yang semakin meningkat menandakan bahwa semakin banyak device berbasis Android sehingga aplikasi ini akan menjadi banyak digunakan orang[3]. Dan android dimanfaatkan untuk mempermudah menjalankan bisnis oleh para pelaku bisnis. Seperti bisnis obat perhiasan, pakaian, dan kuliner. Terkhusus pada aspek bisnis kuliner antara lain : rumah makan, restoran, toko dll [4]. Banyaknya fitur bisnis kuliner yang telah dibuat dalam setiap kemunculan perangkat android. Dimulai dari aplikasi yang dapat memesan menu, hingga pesan antar jemput makanan.

Setiap restoran memiliki SOP untuk menjaga mutu pelayanan dan mutu produk guna untuk kepuasan dan kenyamanan pengunjung. Dalam hal ini restoran perlu menjaga kestabilan mutu pelayanan dan produk agar pengunjung semakin bertambah [5]. Berdasarkan hasil penelitian [6] membuktikan bahwa variabel kualitas pelayanan yang terdiri assurance, emphaty, reliability, responsiveness dan tangible berpengaruh terhadap kepuasan konsumen. Pada umumnya manusia menginginkan segala sesuatu dapat dikerjakan dengan mudah [7], begitu juga dengan para karyawan kuliner dan para pengunjung kuliner. Kebanyakan dari tempat kuliner masih menerapkan sistem tulis untuk melakukan pemesanan menu, penyampaian pesanan pelanggan tiba dengan memakan waktu yang lama yang dikarenakan jarak antar dapur, tulisan catatan pesanan yang kadang sulit untuk terbaca, terselipnya kertas catatan pesanan yang mempengaruhi urutan proses pesanan, dan terdapat pesanan yang terlupa [4]. Serta sulit untuk mencari tempat duduk yang kosong ketika terjadi lonjakan peengunjung yang berdatangan. Pelanggan restoran yang ingin memesan tempat dengan mudah tanpa harus langsung datang ke lokasi tempat kuliner berada, mengetahui tempat-tempat dan informasi kuliner yang ada di kota Palembang dengan mudah, serta dalam pemesanan menu tidak sulit dan cepat dalam proses pembuatannya. Dengan pesatnya perkembangan teknologi inilah yang mampu memberikan solusi dari masalah ini. Sehingga dibuatlah sebuah aplikasi yang dapat memberikan informasi, dapat melakukan pemesanan tempat untuk waktu yang ditentukan oleh pihak pelanggan dan pemesanan menu kuliner yang diinginkan sebelum tiba di tempat kuliner yang bersangkutan.

\section{METODOLOGI PENELITIAN}

Metodologi dalam penelitian ini menggunakan metode waterfall yang dimana metode ini merupakan metode dalam pengembangan aplikasi yang digunakan. Metode waterfall sering disebut dengan metode air terjun yang dimana pada 
tahapannya dikerjakan secara berurutan atau secara linear. Urutan dalam tahapan pengembangan system ini yaitu: analisis, perancangan, implementasi, pengujian dan pemeliharaan. Tahapan metode waterfall dapat dilihat pada gambar 1 . Tahapan analisis merupakan tahapan awal dalam mengumpulkan data yang diperoleh dari sebuah penelitian, studi literature, atau wawancara. Tahapan perancangan aplikasi merupakan sebuah perancangan sistem terhadap solusi dari tahapan sebelumnya.

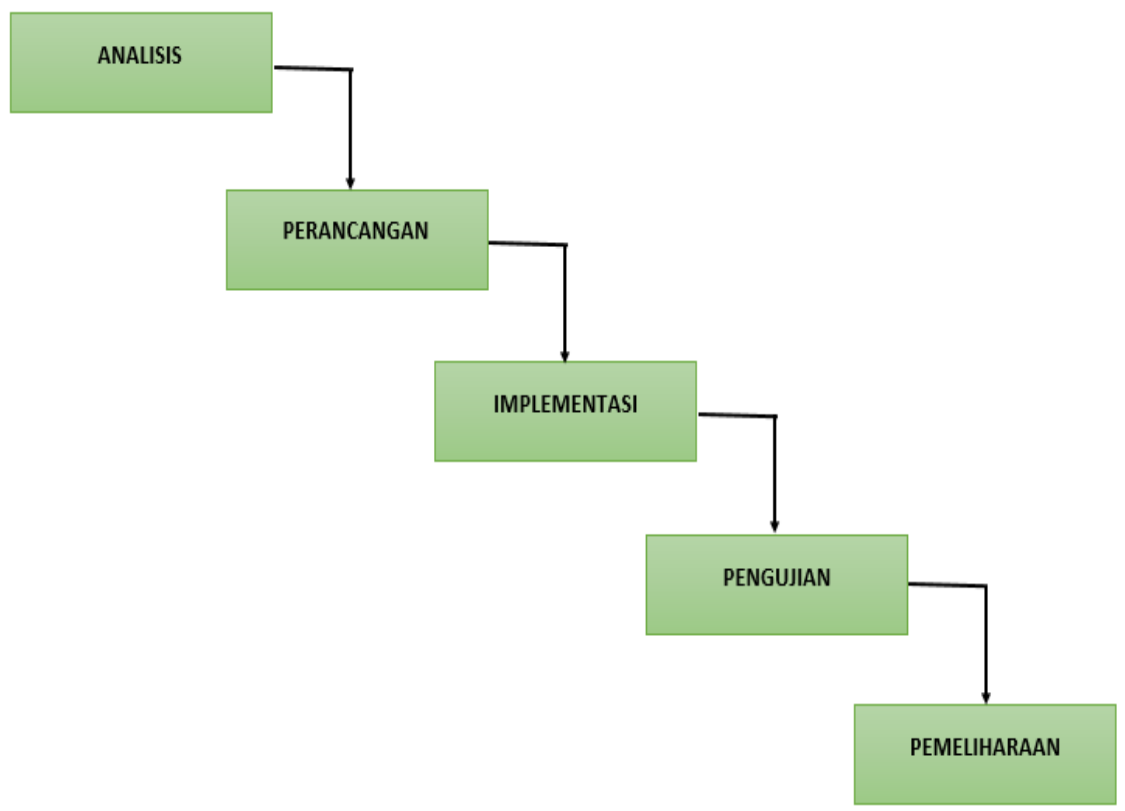

Gambar 1. Metode Waterfall.

\subsection{Perancangan Aplikasi}

Pada tahapan perancangan aplikasi ini dibagi menjadi 4 bagian, yaitu; Use case diagram, activity diagram, perancangan basis data, dan perancangan antar muka.

\subsubsection{Use Case Diagram}

Use Case adalah sebuah interaksi yang saling berhubungan antar actor dan sistemnya itu sendiri. Atau secara umumnya teknik yang digunakan, untuk menumbuhkan sistem informasi, untuk mendapatkan kebutuhan yang fungsional dari sistem yang ada [8]. Di bawah ini merupakan use case diagram yang digunakan dalam tahapan perancangan aplikasi pemesanan tempat restoran kota Palembang. Terdapat fitur-fitur yang dapat diakses oleh user dan admin restoran. 


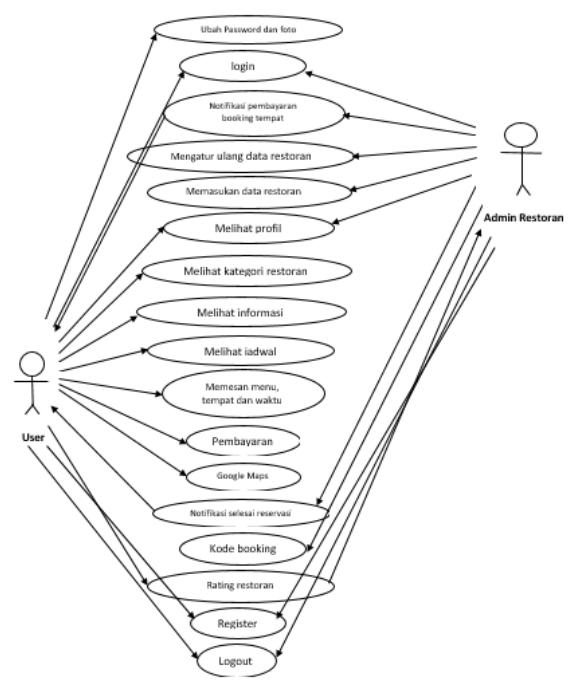

Gambar 2. Use Case Diagram antara User dan Admin Restoran.

\subsubsection{Activity Diagram}

Activity diagram menunjukan berbagai aliran aktivitas dalam sistem perancangan aplikasi yang sedang dikerjakan. Berikut pada gambar 3 merupakan proses aktivitas dalam melakukan pemesanan tempat restoran kota Palembang. Gambar 4 merupakan notifikasi konfirmasi pembayaran dari admin restoran ke user melalui email. Gambar 5 merupakan notifikasi selesai setelah melakukan pelunasan pembayaran pada pihak kasir.

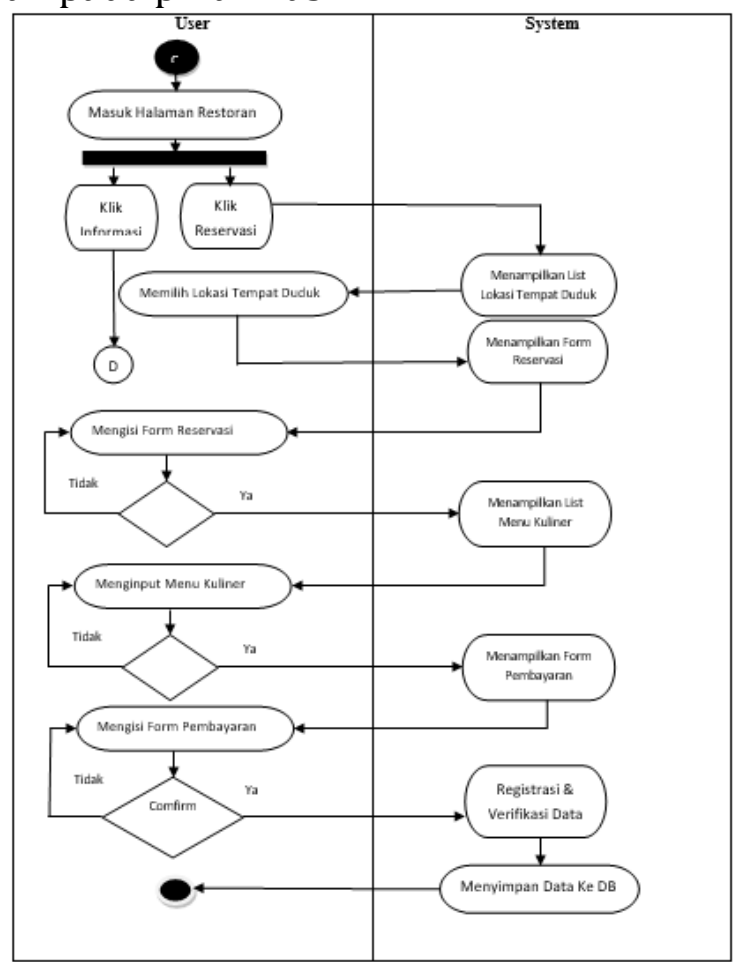

Gambar 3. Activity Diagram Proses Pemesanan Tempat. 


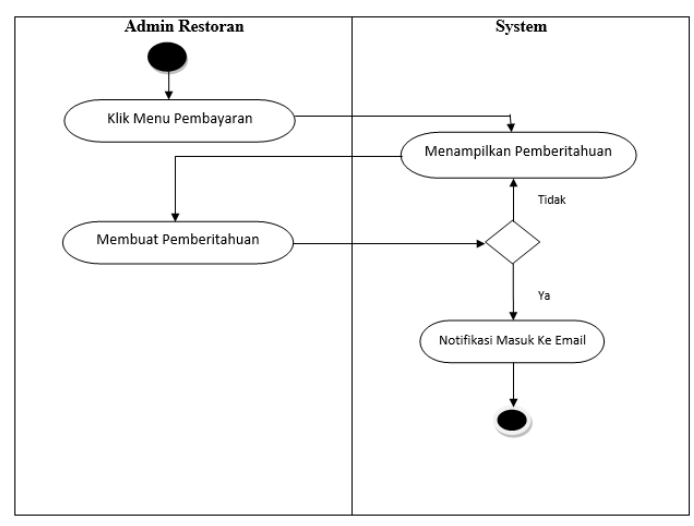

Gambar 4. Diagram Activity Notifikasi Konfirmasi Pembayaran User.

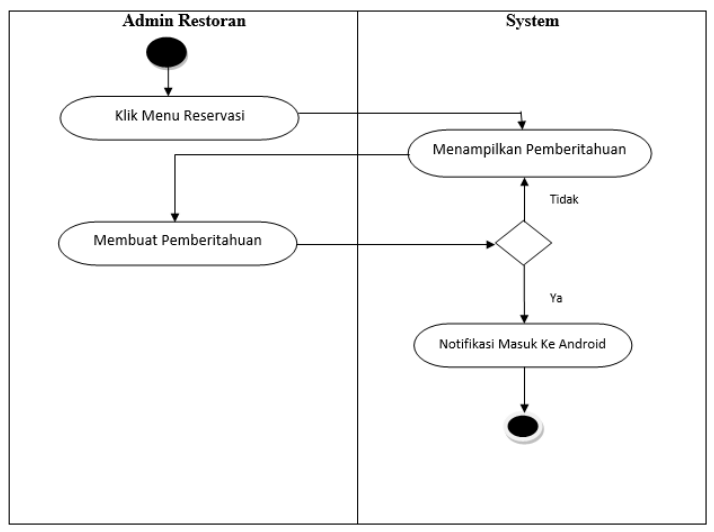

Gambar 5. Diagram Activity Notifikasi Selesai Reservasi.

\subsubsection{Perancangan Basis Data}

Perancangan database merupakan proses yang berguna untuk menentukan isi dan pengaturan data yang dibutuhkan untuk membantu dalam berbagai rancangan sistem [9]. Basis data yaitu kumpulan data yang memiliki satu atau lebih table yang terhubung antara satu dengan yang lainnya, dimana pada setiap User memiliki hak akses agar dapat menggunakannya, seperti edit, delete, update (mengubah, menghapus, memperbarui) dan lainnya pada beberapa table tersebut. Kegunaan atau Fungsi Sistem Basis Data adalah untuk mengatasi berbagai masalah yang terjadi pada saat pemrosesan data dimana dengan menggunakan metode konvensional [10].

Perancangan basis data yang digunakan dalam aplikasi ini adalah server XAMPP dan MySQL sebagai databasenya. Pada gambar 6 merupakan nama database db_aplikasi_r2kplg dan kumpulan table yang berada di PhpMyAdmin. 

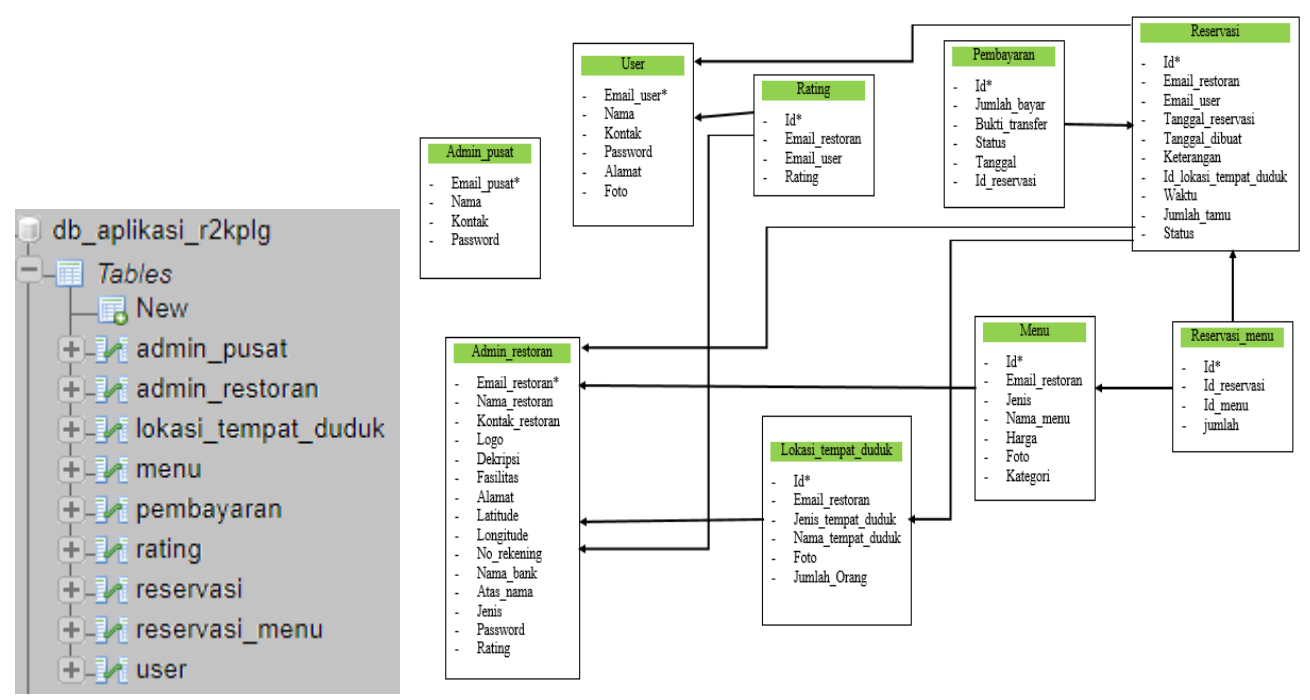

Gambar 6. Database MySQL dan Database Diagram.

\subsubsection{Perancangan Antar Muka}

Di bawah ini merupakan perancangan antar muka dalam proses pemesanan tempat restoran kota Palembang berbasis android.
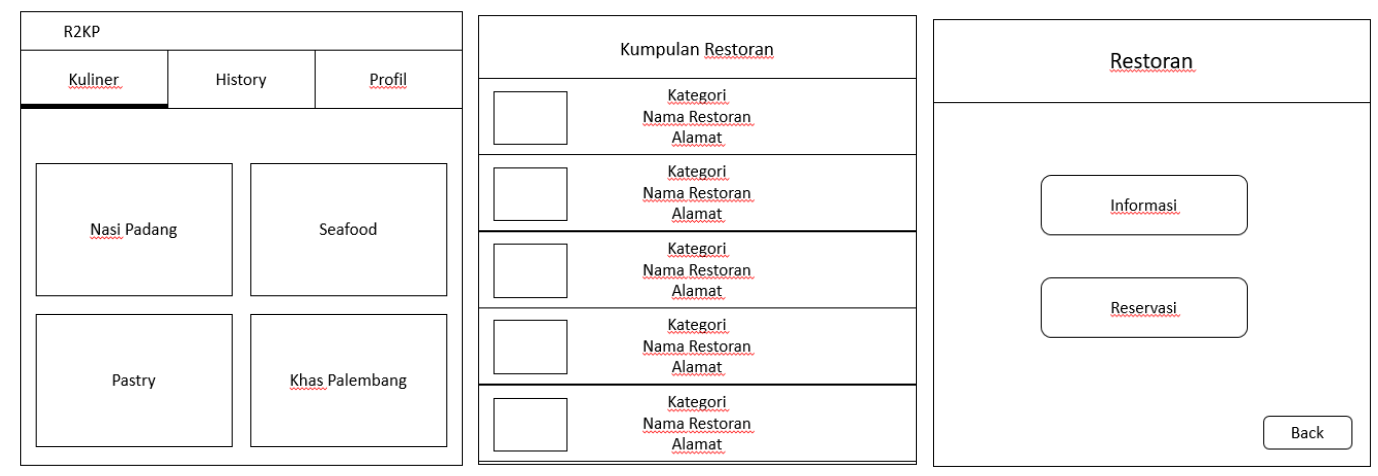

Gambar 7. Perancangan Desain Layout Kategori Kuliner, List Kumpulan Restoran dan Restoran.
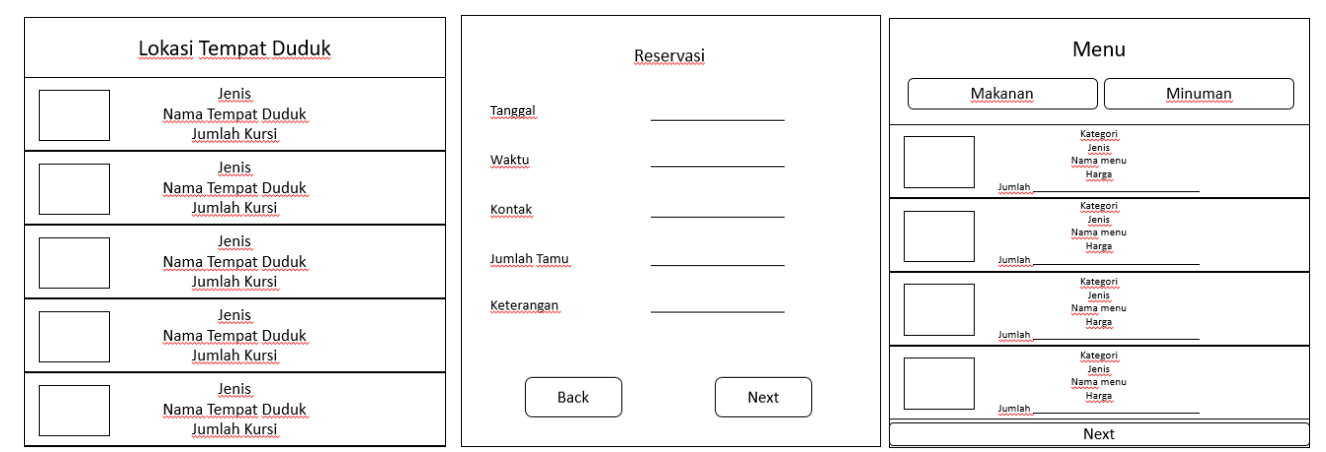

Gambar 8. Perancangan Desain Layout Lokasi Duduk, Reservasi, dan Menu. 

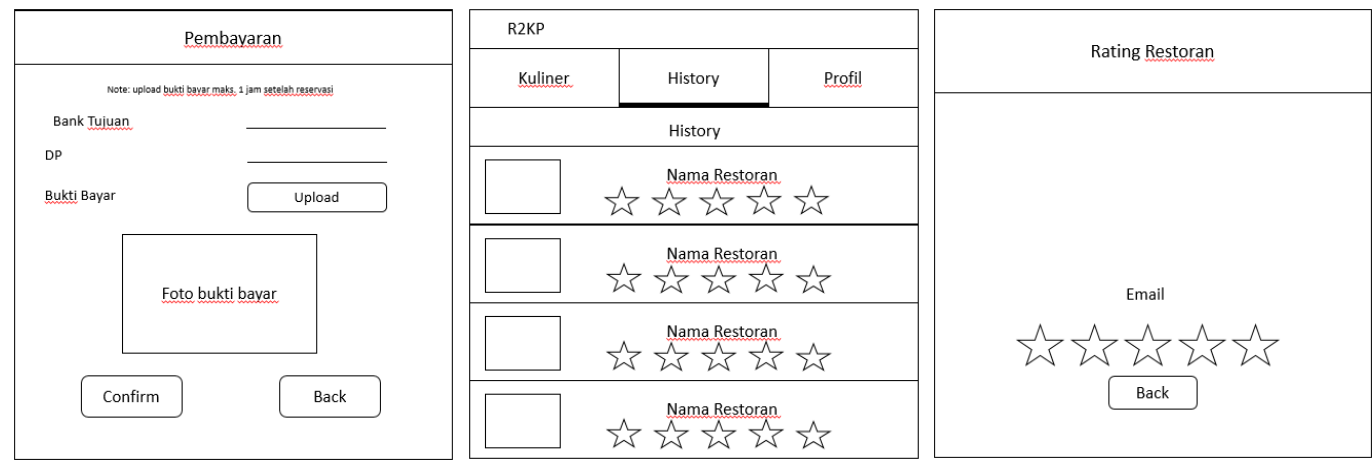

Gambar 9. Perancangan Desain Layout Pembayaran, History, dan Rating.

\subsection{Implementasi}

Tahap implementasi ini merupakan tahap pembuatan program setelah selesai melakukan perancangan aplikasi. Pada perancangan aplikasi ini menggunakan bahasa program Java dan PHP. Software yang digunakan dalam pemrograman aplikasi ini, yaitu: XAMPP, Sublime Text 3, dan Android Studio.

\section{HASIL DAN PEMBAHASAN}

\subsection{Hasil}

Hasil dari aplikasi ini adalah aplikasi pemesanan tempat restoran kota Palembang berbasis android dan web. Aplikasi berbasis android dikhususkan untuk user/pelanggan dan memberikan fitur seperti informasi restoran, pemesanan tempat, dapat memilih menu kuliner yang ada, melakukan pembayaran tempat pembookingan, dapat memberikan rating terhadap tempat kuliner yang telah dikunjungi, dapat memilih kategori wisata kuliner dari ke-4 sampel, dan informasi data pribadi. Aplikasi berbasis web ini digunakan oleh admin restoran dimana isi dari fitur yang diberikan hampir sama tetapi fungsinya berbeda, seperti: Menginput dan meng-update data seperti; informasi restoran, menu kuliner, dan lokasi tempat duduk, melihat, mengedit dan menghapus data pada pembayaran, reservasi dan reservasi menu dari pihak user, serta dapat melihat rating.

Cara kerja dari ke-2 aplikasi ini adalah aplikasi web admin restoran akan terhubung dengan aplikasi mobile dari user sehingga admin restoran dan user dapat saling mengirim data melalui sistem yang telah dibuat secara berkala dan memastikan data yang dikirim tersebut merupakan data yang terbaru.

Berikut merupakan struktur dari aplikasi pemesanan tempat restoran kota Palembang berbasis android. 


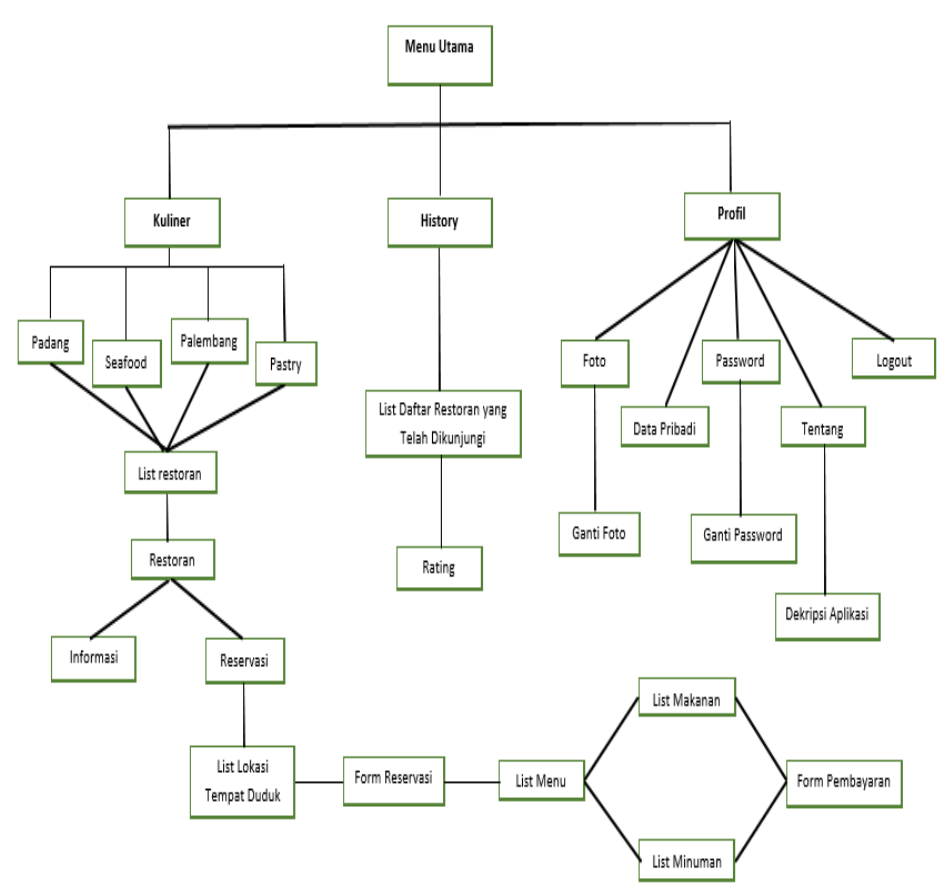

Gambar 10. Struktur Aplikasi Mobile.

\subsection{Pembahasan}

\subsubsection{Aplikasi Mobile}

Pengujian dari aplikasi mobile ini telah dilakukan dengan menggunakan emulator dan perangkat android yang memiliki spesifikasi Android Lolipop seperti Android Vivo Y21. Dari pengujian ini pada aplikasi pemesanan tempat restoran maka hasil yang didapatkan hasil halaman antar muka yang terdiri dari register, login, splash screen, menu utama, profil pribadi, ganti password, ganti foto profil user, tentang, 4 jenis kuliner, list kumpulan restoran, restoran, informasi restoran, list tempat lokasi duduk, form pemesanan, list menu kuliner (makanan dan minuman), form pembayaran, history, dan rating.
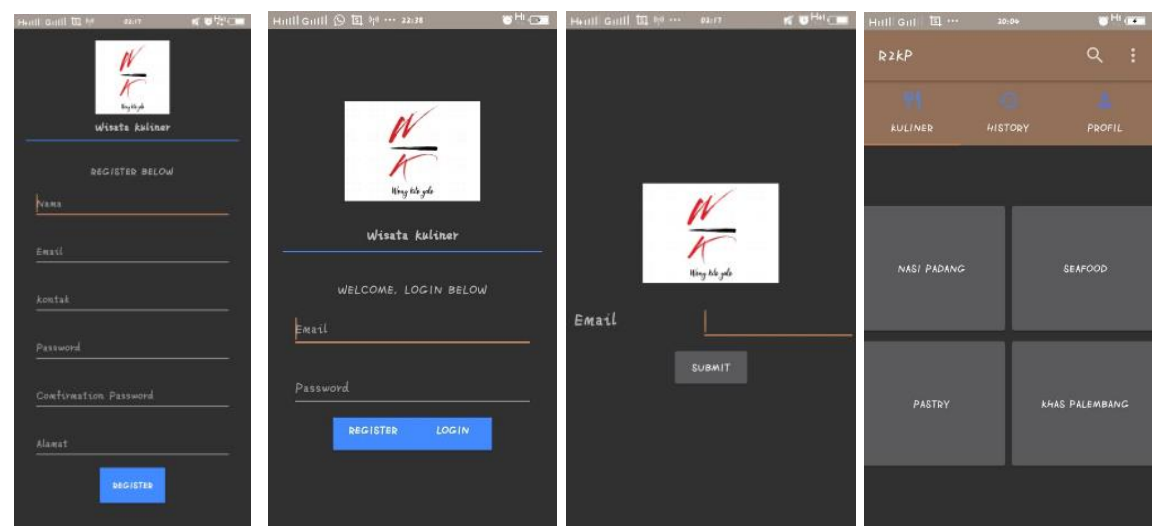

Gambar 11. Register, Login, Lupa Pass. dan Menu Utama. 
Pada halaman menu utama ini menggunakan tablayout dan terdiri dari 3 tab view yaitu kuliner, history dan profil. Pada halaman kuliner terdiri dari 4 button sampel kuliner yang digunakan seperti nasi Padang, seafood, pastry, dank has Palembang.
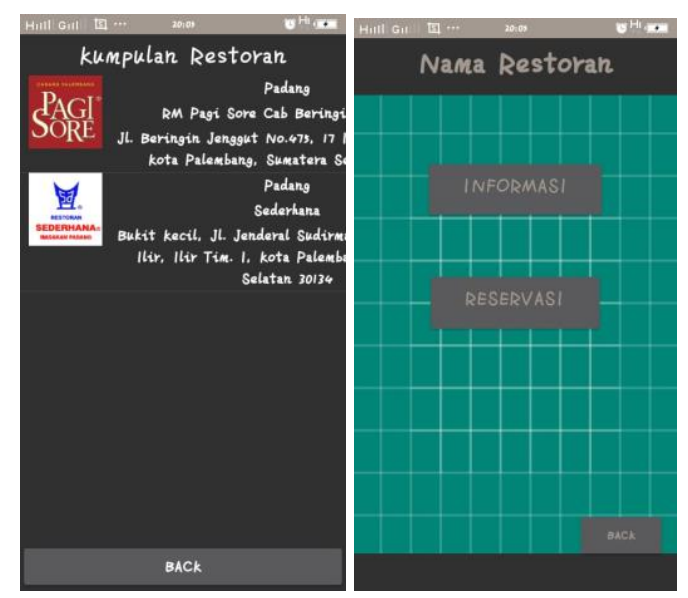

Gambar 12. List Kumpulan Restoran dan Restoran.

Pada halaman list kumpulan restoran ini menggunakan 2 sampel restoran di setiap masing-masing kategori kuliner. Pada halaman restoran terdapat 2 button yaitu informasi dan reservasi. Pada halaman informasi memberikan beberapa informasi mengenai restoran tersebut (sejarah restoran, fasilitas yang diberikan, cp dan alamat restoran).
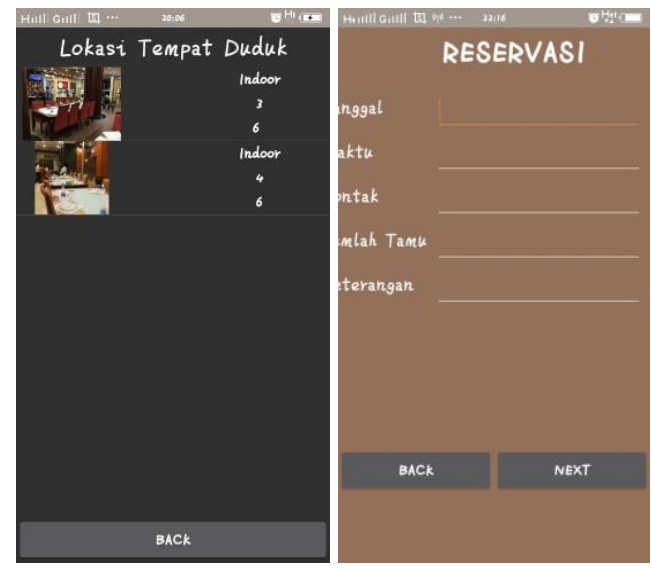

Gambar 13. List Kumpulan Lokasi Tempat Duduk.

Pada halaman ini, user menginput tanggal dan waktu pemesanan tempat, kontak user yang dapat dihubungi, jumlah tamu yang akan berkunjung, dan keterangan apabila terdapat permintaan khusus dari pelanggan. 


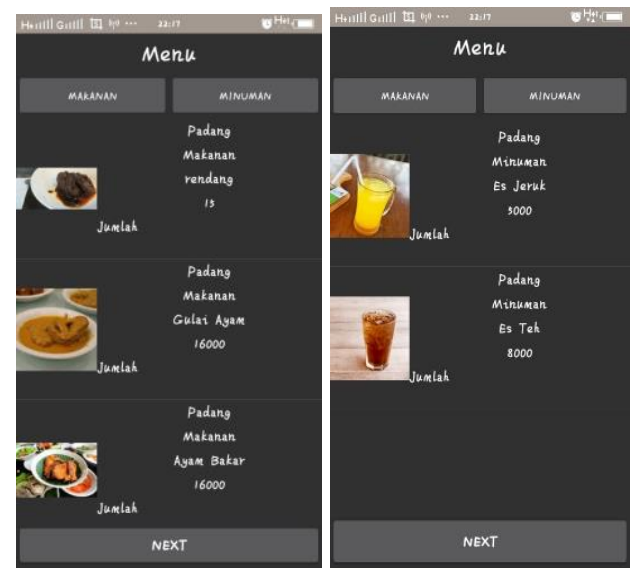

Gambar 14. Menu Kuliner.

Pada halaman menu kuliner ini dibagi menjadi 2 bagian yaitu: makanan dan minuman. Pada halaman ini, user dapat melihat menu apa saja yang bisa disajikan oleh pihak restoran dan dilengkapi dengan data seperti jenis kuliner yang telah dipilih, kategori (makanan dan minuman) yang ingin dipesan, nama menu, harga dan dapat menginput jumlah menu yang ingin dipesan. Di bawah ini merupakan halaman penginputan menu.

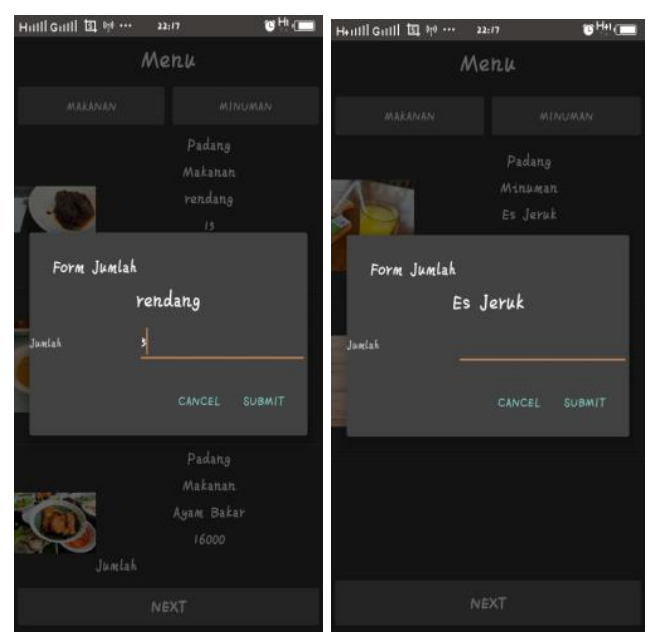

Gambar 15. Input Jumlah Menu. 


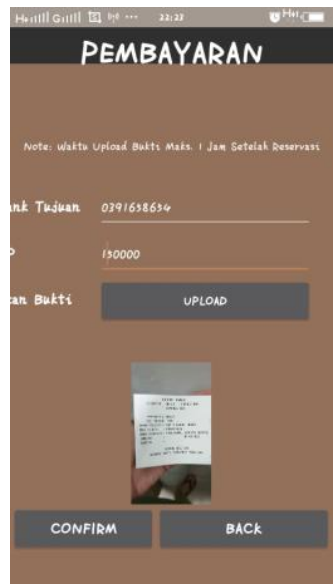

Notifikasi Reservasi Restoran Kota Palembang Kotak Masuk x
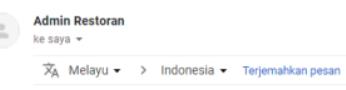

Terima kasih telah melakukan reservasi.

Balas -10

Gambar 16. Form Pembayaran dan Notifikasi Konfirmasi Pembayaran.

Pada halaman pembayaran, user menginput bank tujuan yang telah diperoleh dari informasi restoran, dp yang telah ditentukan, dan scan bukti pem-booking-an tempat. Lalu klik button confirm dan akan di konfirmasi oleh pihak admin restoran melalui email. Gambar 16 yg ke-2 merupakan notifikasi konfirmasi dari pihak admin restoran.
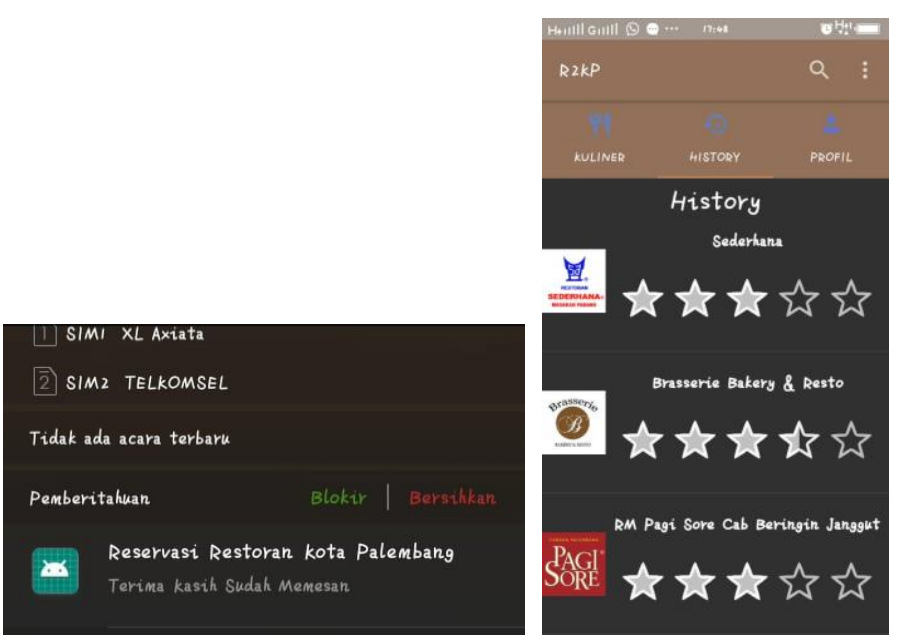

Gambar 17. Notifikasi Selesai Pemesanan Tempat dan History.

Pada halaman ini admin restoran akan mengirim notifikasi setelah berkunjung dan secara otomatis data restoran berupa nama, logo, dan rating akan masuk ke halaman history / daftar riwayat restoran. User dapat memberikan rating dengan mengklik restoran tersebut. lalu akan muncul halaman rating seperti pada gambar 18. 


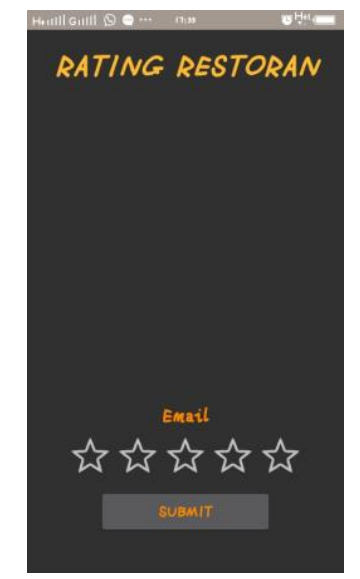

Gambar 18. Rating.

Pada halaman rating, user dapat menginput nilai dari semua aspek restoran.

\subsubsection{Aplikasi Web}

Adapun hasil antar muka yang didapat dari hasil pengujian aplikasi web admin restoran yaitu terdiri dari login, menu utama, dan beberapa sub menu.

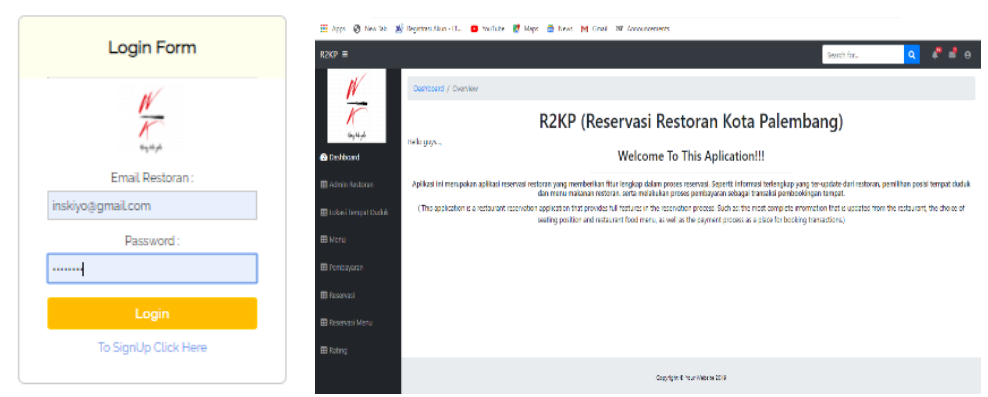

Gambar 19. Login Admin Restoran dan Dashboard.

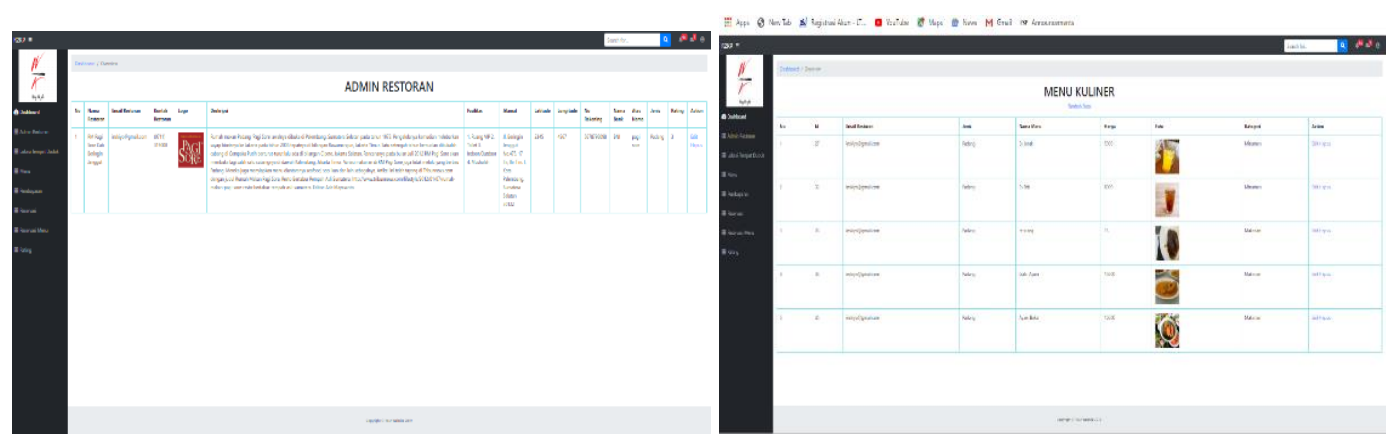

Gambar 20. Data Informasi dan Kumpulan Menu Kuliner Restoran.

Pada halaman di gambar 20 merupakan salah satu halaman dari beberapa table yang dapat melihat, mengubah dan menambah data dari restoran bersangkutan. 


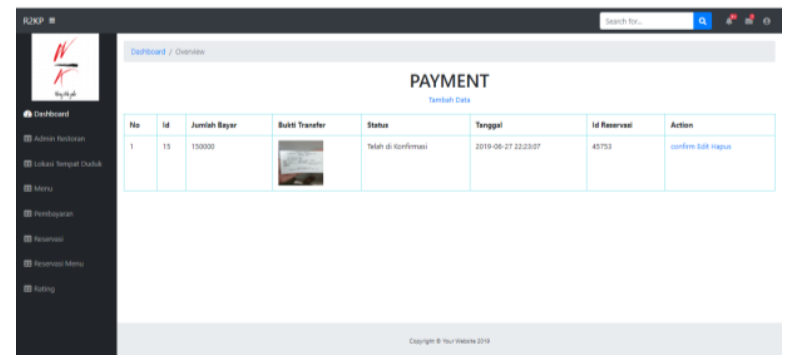

Gambar 21. Data Pembayaran.

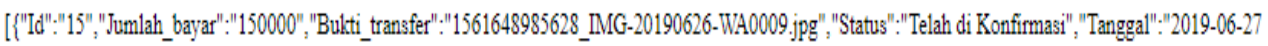

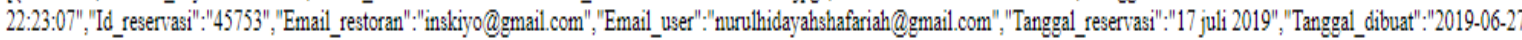

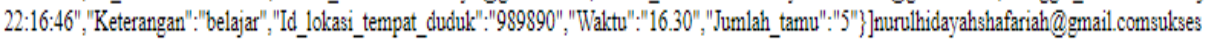

Gambar 22. Hasil Konfirmasi Pembayaran dari Pihak Admin Restoran.

Pada halaman Payment terdapat tambahan action button yaitu confirm yang berguna untuk mengkonfirmasi bukti pembayaran dari user/pelanggan dan pada gambar 22 akan tertampil halaman bukti pengiriman konfirmasi kepada user melalui email yang bisa dilihat di gambar 16 ke-2 pada bagian aplikasi mobile.

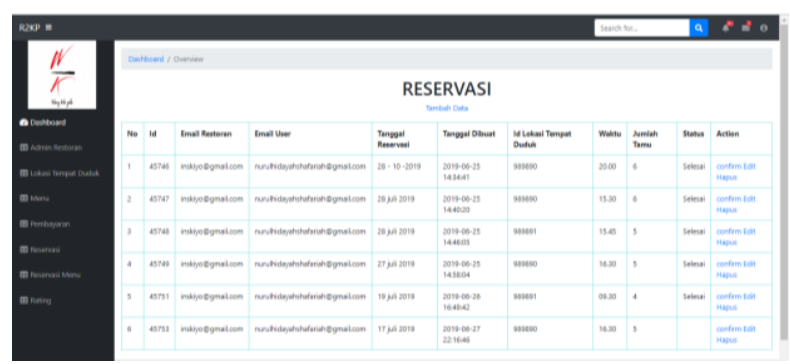

Gambar 23. Data Reservasi.

Pada gambar 23 terdapat tambahan action yaitu button confirm yang digunakan oleh pihak admin restoran sebagai bukti bahwa pelanggan telah selesai dan melunasi sisa hasil pemesanannya. Dan notifikasinya dikirim melalui android dapat dilihat pada gambar $17 \mathrm{ke}-1$.

\subsection{Analisa}

Pada aplikasi ini dilakukan pengujian yaitu salah satunya pada bagian pemesanan tempat. Pada halaman restoran klik button reservasi dan akan muncul halaman list restoran. Disini user dapat memilih lokasi tempat duduk yang akan dipesan. Setelah mengklik lokasi tersebut maka akan tertampil halaman form reservasi. Lalu user akan menginput semua pada daftar form dan klik button next. Lalu masuk pada halaman list menu kuliner dan menginput jumlah menu yang akan dipesan dan klik next. Kemudian user melakukan pembayaran melalui atm, m-banking, dll. Setelah pembayaran telah selesai, maka user akan mengkonfirmasi pembayaran booking tempat restoran pada halaman pembayaran. Di sana terdapat nama bank yang dituju, jumlah pembayaran booking tempat, dan bukti transfer ke 
no. rekening restoran dan klik confirm jika data yang telah dimasukkan benar. Maka admin restoran akan mengkonfirmasi di halaman pembayaran dan diteruskan melalui email. Setelah user datang ke lokasi dan selesai melakukan reservasi dan melunasi segala pemesanan, maka pihak admin di halaman reservasi akan mengkonfirmasi selesai. Pada aplikasi mobile user akan mendapatkan notifikasi selesai pemesanan tempat dan secara otomatis akan tercatat pada history sebagai daftar riwayat restoran yang telah dikunjungi dan user dapat memberikan rating restoran.

\section{SIMPULAN}

Aplikasi ini dibangun dengan metode waterfall. Bahasa program yang dibuat dalam aplikasi ini adalah Java, php dan MySQL sebagai basis datanya. Aplikasi pemesanan tempat restoran kota Palembang yang telah dibangun dapat bekerja dengan baik pada Android yang memiliki spesifikasi lollipop. Tetapi pada hasil pengujian aplikasi terdapat posisi-posisi tulisan yang masih terpotong dan sedikit bergeser dari posisi yang telah diatur. Hal ini disebabkan oleh ukuran layar perangkat android yang berbeda-beda. Untuk perkembangan selanjutnya diharapkan dapat memberikan fitur-fitur yang terbaru seperti pengubahan system pembayarannya dan desain yang menarik.

\section{DAFTAR PUSTAKA}

[1] DKatadata.co.id. 2017 [Online] Available: https://databoks.katadata.co.id/datapublish/2017/10/09/73-perangkat-mobile-globalmenggunakan-android

[2] Matsun, Ramadhani, Dochi., and Lestari, Isnania., "Perancangan Media Pembelajaran Listrik Magnet Berbasis Android Di Program Studi Pendidikan Fisika Ikip Pgri Pontianak", Jurnal Pendidikan Informatika dan Sains p-ISSN: 2089-2802 Vol.7 No. 1, Juni 2018.

[3] Akbar, Muhammad., Satoto, Iman, Kodrat., and Isnanto, Rizal, R. "Pembuatan Aplikasi Layanan Pesan Antar Makanan Pada Sistem Operasi Android.

[4] Agustina, Rini., Suprianto, Dodit., and Muslimin, Ikhwanul. “Analisis Perancangan Pemesanan Makanan Menggunakan SmartPhone Berbasis Android”.STIKI Informatika Jurnal, Vol. 7, No. 2, October 2017.

[5] A. Khusnul, Lica., and N. K. Ugie, Yolanda. "Pelayanan Restoran Dalam Menciptakan Kepuasan Pelanggan'.

[6] Jamin, Fadly, Khaerul. “Analisis Sisten Pelayanan Terhadap Tingkat Kepuasan Konsumen pada Restoran Seafood Di Kota Makassar". 2014.

[7] Tompoh, Forman, Jos., R. Sentinuwo, Steven., and Sinsuw, E. A. Alicia. "Rancang Bangun Aplikasi Pemesanan Menu Makanan Restoran Berbasis Android". E-Journal Teknik Informatika, Vol. 9, No. 1, Oktober 2016.

[8] Salamadian Muda dan Berilmu. 2018. [Online] Available: https://salamadian.com/pengertianuse-case-diagram-adalah/

[9] Falani, Zaki, Achmad. "Perancangan Basis Data". Available: https://www.academia.edu/7517964/PERANCANGAN-BASIS-DATA

[10]Ruangguru.co.id. 2018. Available: https://www.ruangguru.co.id/pengertian-basis-data-dansistem-basis-data-definisi-tujuan-fungsi-dan-komponennya/ 